\title{
Focus on vulnerable populations and promoting equity in health service utilization --an analysis of visitor characteristics and service utilization of the Chinese community health service
}

\author{
Xiaoxin Dong ${ }^{1}$, Ling Liu', Shiyi Cao', Huajie Yang ${ }^{1}$, Fujian Song ${ }^{2}$, Chen Yang ${ }^{1}$, Yanhong Gong ${ }^{1}$, Yunxia Wang ${ }^{1}$,
} Xiaoxu Yin ${ }^{1}$, Xing $\mathrm{Xu}^{1}$, Jun Xie ${ }^{1}, \mathrm{Yi} \mathrm{Sun}^{1}$ and Zuxun Lu${ }^{1^{*}}$

\begin{abstract}
Background: Community health service in China is designed to provide a convenient and affordable primary health service for the city residents, and to promote health equity. Based on data from a large national study of 35 cities across China, we examined the characteristics of the patients and the utilization of community health institutions (CHIs), and assessed the role of community health service in promoting equity in health service utilization for community residents.

Methods: Multistage sampling method was applied to select 35 cities in China. Four CHls were randomly chosen in every district of the 35 cities. A total of 88,482 visitors to the selected $\mathrm{CH}$ ls were investigated by using intercept survey method at the exit of the CHIs in 2008, 2009, 2010, and 2011. Descriptive analyses were used to analyze the main characteristics (gender, age, and income) of the CHI visitors, and the results were compared with that from the National Health Services Survey (NHSS, including CHIs and higher levels of hospitals). We also analyzed the service utilization and the satisfactions of the $\mathrm{CHI}$ visitors.

Results: The proportions of the children (2.4\%) and the elderly (about 22.7\%) were lower in our survey than those in NHSS (9.8\% and 38.8\% respectively). The proportion of the low-income group (26.4\%) was apparently higher than that in NHSS (12.5\%). The children group had the lowest satisfaction with the CHIs than other age groups. The satisfaction of the low-income visitors was slightly higher than that of the higher-income visitors. The utilization rate of public health services was low in $\mathrm{CH}$ s.

Conclusions: The CHIs in China appears to fulfill the public health target of uptake by vulnerable populations, and may play an important role in promoting equity in health service utilization. However, services for children and the elderly should be strengthened.
\end{abstract}

Keywords: Equity in health service utilization, Community health service, Visitor characteristics, Satisfaction

\section{Background}

In 1978, the Declaration of Alma-Ata formally adopted primary health care (PHC) by the World Health Organization (WHO) as the means for providing a comprehensive, universal, equitable, and affordable healthcare service for all countries [1]. Community health service (CHS) is the main form of PHC. Since the 1960s, many countries have

\footnotetext{
* Correspondence: zuxunlu@yahoo.com

${ }^{1}$ School of Public Health, Tongji Medical College, Huazhong University of Science and Technology, Wuhan, China

Full list of author information is available at the end of the article
}

attached importance to the organizational construction and the functional expansion of the CHS. For example, CHS facilities in England provide accessible primary care free of charge [2]. Beginning in the 1970s, Canada introduced community-oriented, multidisciplinary $\mathrm{CHS}$, which focused on social justice and equity [3]. South Africa has implemented the policy of "Universal access to PHC for all South Africans" from 1994 and ever since, the community health institutions (CHIs) have contributed to improving the utilization of $\mathrm{PHC}$ [4]. 
In China, patients can usually choose the health service providers they prefer, and pay the chosen provider directly out-of-pocket. The competition stimulates the health service institutions to update facilities and equipment, enlarge scale, enroll excellent physicians by offering liberal salaries and benefits, and adopt a positive attitude towards patients' preferences [5]. Consequently, superior health resources and patients concentrate at the secondary-tiered and third-tiered health service institutions, while there is a decline in the utilization of PHC institutions. This results in a serious equity problem, especially with regard to low-income patients who cannot afford high costs of health services. Health equity is the absence of systematic and potentially remediable differences in one or more aspects of health across populations or population groups defined socially, economically, demographically, or geographically [6]. Achieving health equity usually involves ensuring that disadvantaged sectors of the population can both afford and gain access to relevant health services. Reducing health inequities is, for the WHO Commission on Social Determinants of Health, an urgent and ethical imperative [7]. In 1997, the Chinese government endeavored to develop a convenient and affordable primary health service -CHS -for the city residents to meet the PHC need of all populations, especially vulnerable populations who experience limited resources and consequent high relative risk of morbidity and premature mortality [8], and to promote health equity.

Chinese CHIs are divided into two levels: health centers and health stations. A health center covers 30,000 to 50,000 residents and can be equipped with inpatient beds, while a station covers about 3,000 residents and isn't equipped with inpatient beds [5]. Both health centers and health stations provide outpatient service and emergency service. Patients can seek medical services (including diagnosis and treatment, purchasing medicines, and rehabilitation) and public health services (including health check, preventive care, and health education) in CHIs. By the end of 2010, 98\% of cities in mainland China have established CHS systems, including 6,903 centers and 25,836 stations in total [9].

For the 21st century, equity in health service utilization remains a major concern, as an important aspect of the health equity. With the rapid development of the Chinese CHS $[5,10,11]$, a more policy relevant question is whether the CHS system in China is doing what it's designed to do, what's the effect of CHS system on meeting the PHC need of vulnerable populations, or further what's the role of CHS system in promoting equity in health service utilization. There is a lack of studies on this issue [12-14]. Thus, we conducted a four-year continuous investigation on the visitors of CHIs with a large sampling size at the national level. By analyzing the visitors' demographic characteristics, and comparing that with 2008 National
Health Services Survey (NHSS) in Chinese cities [15], we aimed to assess whether CHIs attracted vulnerable populations to seek for health services. The NHSS was a sampling survey of visitors of all levels of health institutions nationwide (including CHIs). We also analyzed the service types used by different visitors (especially the vulnerable populations) and their satisfactions. The purposes were to investigate what types of services they were likely to use and whether they were satisfied, and then to grasp what aspects of the services should be improved to better serve the patients.

\section{Methods}

\section{Questionnaire design and content}

The study was approved by the Research Ethics Committee in Huazhong University of Science and Technology, Wuhan, China. Data were collected using a self-administered uniform questionnaire. The questionnaire was developed in three steps. Firstly, a pool of indicators was formed after literature reviews. Secondly, the indicator pool was modified and established through two rounds of Delphi questionnaire requiring quantitative and qualitative answers. Finally, the questionnaire was further revised after a field pretest. The questionnaire included three parts. The first part was demographic characteristics of the visitors. The second part was the utilization of health services. And the third one was whether the visitors were satisfied with certain aspect of health services. The satisfaction was divided into five levels: very satisfying, satisfying, neutral, dissatisfying and very dissatisfying. Only the ones who choose the levels of very satisfying or satisfying were regarded as being satisfied.

\section{Sampling frame and sampling methods}

The sample size of this study was based on the method recommended by the NHSS in China [15], which suggested that a sample of 24 cities and around 20,000 people would be representative of the target population. Cities were classified according to the World Bank classification (Gross National Income (GNI) per capita, Atlas method) [16,17]: the developed eastern cities, less developed western cities and the central cities between the two. The study selected 35 cities, including 14 eastern cities, 9 central cities, and 12 western cities. The cities were further divided into city districts (The district is the administration division under the city, and a city includes 5-7 districts in average). These cities were selected by the multistage sampling according to socio-economic characteristics, city size, and the development level of CHS. Two centers and two stations were randomly chosen in every district of these 35 cities. Thirty visitors of each center and twenty visitors of each station were surveyed by intercept survey method at the exit of CHIs. The same survey 
was repeatedly conducted in four years: 2008, 2009, 2010, and 2011.

Valid survey data were available for a total of 88,482 $\mathrm{CHI}$ visitors in four years, including 20,013 visitors in $2008,22,711$ visitors in 2009, 22,430 visitors in 2010, and 23,328 visitors in 2011. Visitors included in these surveys served as a representative sample of the overall visitors of the Chinese CHS $[18,19]$.

\section{Data collection and quality control}

The study was organized and coordinated by the Chinese Ministry of Health. According to the study protocol, the Health Bureau of each city provided training to senior investigators, and the trained senior investigators provided training to junior investigators. Then the trained junior investigators carried out the survey on the visitors at the exit of CHIs. The junior investigators daily checked the collected questionnaires to correct the logic errors and try their best to replenish the missing items during the survey. According to the rechecking ratio (5\%) used in the NHSS [15], the senior investigators randomly selected $5 \%$ from the finished questionnaires to check at the end of the survey. The data was double-blindly entered by two different persons.

\section{Data analysis}

A database was set up with EpiData3.0, and data were analyzed by SAS 9.2.

We analyzed the frequencies, compositions, and trends of the main characteristics of $\mathrm{CHI}$ visitors in terms of gender, age, and income. The visitors whose age were less than 15, between 15 and 65 , and equal to or more than 65 were assigned to group of children, adults and the elderly respectively. Fifty percent of the median or average income is often applied as the low-income line for the country or region internationally [20]. In this study, we applied the $50 \%$ of the mean of the family average monthly income to define the low-income group. In order to illustrate whether CHIs attracted vulnerable populations, we compared the visitor characteristics (gender, age and income) in our study with that of the 2008 NHSS in Chinese cities [15]. The NHSS investigated a nationally representative sample of visitors of all levels of health institutions (including CHIs). Chi-square was used to comparatively analyze the association of the service types used and the satisfactions of CHS with main visitor characteristics based on the data of 2011.

\section{Results}

\section{Main characteristics of $\mathrm{CHI}$ visitors}

The proportion of male and female visitors was 43.5\% and 56.5\% respectively in 2011 (Table 1 and Figure 1). The proportion of the children under the age of 15 was $2.4 \%$ in $2008,2.1 \%$ in $2009,0.5 \%$ in 2010 , and $2.1 \%$ in
2011, while the proportion of the elderly visitors over the age of 65 was $22.7 \%, 23.4 \%, 22.8 \%$, and $23.3 \%$ respectively. The proportions of the children visitors and the elderly visitors were both lower than that estimated by NHSS (Table 1 and Figure 2). The proportion of the low-income patients who used CHIs was $26.4 \%$ in 2008, $20.9 \%$ in $2009,16.7 \%$ in 2010 , and $19.0 \%$ in 2010 , which was apparently higher than $12.5 \%$ in 2008 estimated by NHSS (Table 1 and Figure 3).

\section{Use of $\mathrm{CHI}$ services and visitor characteristics}

The use of $\mathrm{CHI}$ services was divided into two types: medical services (including disease diagnosis and treatment, purchasing medicines, and rehabilitation) and public health services (including health check, preventive care, and health education).

There were differences in distributions of service types used by different groups of visitors in terms of gender $(\mathrm{p}<0.001)$, age $(\mathrm{p}<0.0001)$, and income $(\mathrm{p}<0.05)$, although the absolute differences were generally small (Table 2). The proportions of male visitors who used medical services were slightly higher than female visitors, while the proportions of male visitors using public health services were slightly lower than female visitors.

The utilization rates of disease diagnosis and treatment services were high for patients of all ages $(49.2 \%$ for children, $39.6 \%$ for adults, and $40.7 \%$ for elderly patients). Purchasing medicine services were used mainly by adult patients (3.6\% for children, $24.1 \%$ for adults and 19.9\% for the elderly). The use of rehabilitation services was low for patients of all ages (1.6\% to 3.3\%). Health check services were mainly used by adult patients $(14.4 \%$ to $18.9 \%$ ), and preventive care services mainly used by children (39.2\%). Many elderly patients visited CHIs for health education (11.7\%).

\section{Visitors' satisfaction of $\mathrm{CHI}$ services}

Female visitors were more satisfied with $\mathrm{CHI}$ services than male visitors in terms of their perceptions of privacy protection and avoidance of excessive examination or over-prescription (Table 3). For the different age groups, the elderly group was more satisfied than other groups in convenience, waiting time, environment, service providers' attitude, respect to patients, equipment, explanation and communication, service and drug prices, and privacy, while the children group was more satisfied in avoidance of excessive examination or over-prescription. As to the different income groups, the low-income group had higher satisfaction in waiting time, environment, service providers' attitude, respect to patients, equipment, and privacy than the higher-income group.

In general, the overall satisfactions of female, elderly, and low-income visitors were slightly higher than other corresponding groups (Table 3). 
Table 1 The compositions of the visitors of different characteristics in CHIs and NHSS

\begin{tabular}{|c|c|c|c|c|c|c|c|c|c|c|c|}
\hline & & \multicolumn{2}{|c|}{ NHSS in 2008 (city) } & \multicolumn{2}{|c|}{2008} & \multicolumn{2}{|c|}{2009} & \multicolumn{2}{|c|}{2010} & \multicolumn{2}{|c|}{2011} \\
\hline & & $n$ & $\%$ & $n$ & $\%$ & $n$ & $\%$ & $n$ & $\%$ & $n$ & $\%$ \\
\hline \multicolumn{2}{|r|}{ Total } & 6474 & - & 20013 & - & 22711 & - & 22430 & - & 23328 & - \\
\hline \multirow[t]{2}{*}{ Gender } & Male & 2892 & 44.7 & 8906 & 44.5 & 10224 & 45.0 & 9566 & 42.6 & 10157 & 43.5 \\
\hline & Female & 3582 & 55.3 & 11107 & 55.5 & 12487 & 55.0 & 12864 & 57.4 & 13171 & 56.5 \\
\hline \multirow[t]{7}{*}{ Age } & $0 \sim 14$ & 636 & 9.8 & 471 & 2.4 & 468 & 2.1 & 103 & 0.5 & 483 & 2.1 \\
\hline & $15 \sim 24$ & 169 & 2.6 & 1356 & 6.8 & 1400 & 6.2 & 1371 & 6.1 & 1355 & 5.8 \\
\hline & $25 \sim 34$ & 288 & 4.5 & 3304 & 16.5 & 3861 & 17.0 & 3666 & 16.3 & 4193 & 18.0 \\
\hline & $35 \sim 44$ & 615 & 9.5 & 3528 & 17.6 & 3897 & 17.2 & 3974 & 17.7 & 3844 & 16.5 \\
\hline & $45 \sim 54$ & 1013 & 15.6 & 3497 & 17.5 & 3888 & 17.1 & 4082 & 18.2 & 3806 & 16.3 \\
\hline & $55 \sim 64$ & 1243 & 19.2 & 3311 & 16.6 & 3889 & 17.1 & 4117 & 18.4 & 4215 & 18.1 \\
\hline & $65+$ & 2509 & 38.8 & 4546 & 22.7 & 5310 & 23.4 & 5117 & 22.8 & 5433 & 23.3 \\
\hline \multirow[t]{2}{*}{ FAMI } & Low-income & 811 & 12.5 & 5286 & 26.4 & 4756 & 20.9 & 3745 & 16.7 & 4429 & 19.0 \\
\hline & Higher-income & 5663 & 87.5 & 14727 & 73.6 & 17955 & 79.1 & 18685 & 83.3 & 18899 & 81.0 \\
\hline
\end{tabular}

$\mathrm{CHIs}=$ community health service institutions, NHSS = National Health Services Survey, $\mathrm{FAMI}=$ family average monthly income.

The ones whose age were less than 15 , between 15 and 65 , and equal to or more than 65 were assigned to group of children, adults and the elderly respectively.

\section{Discussion}

The present study showed that the proportion of female visitors of Chinese CHIs was $55.3 \%$ - 57.4\%, close to $55.3 \%$ reported by NHSS. Similar proportions were reported in other counties such as UK (64.1\%) [21], Canada (65.0\%) [3], Australia (51.8\%) [22], United Arab Emirates (57.0\%) [23] and South Africa (66.6\%) [24].

The proportion of children in CHI visitors was apparently lower than that of NHSS. A study elsewhere has suggested that the training of doctors for child health care was limited in CHIs [25]. Nowadays, most Chinese families have only one child. Parents attach great importance to their child's health, and are more likely to seek health care in higher level hospitals when their children get sick [26]. Furthermore, our study indicated that the overall satisfaction of the children group was the lowest. As to the elderly, the proportion was also lower than that of the NHSS. This may be because old patients are more likely to have chronic diseases requiring hospitalization [15], but most CHIs in China do not provide

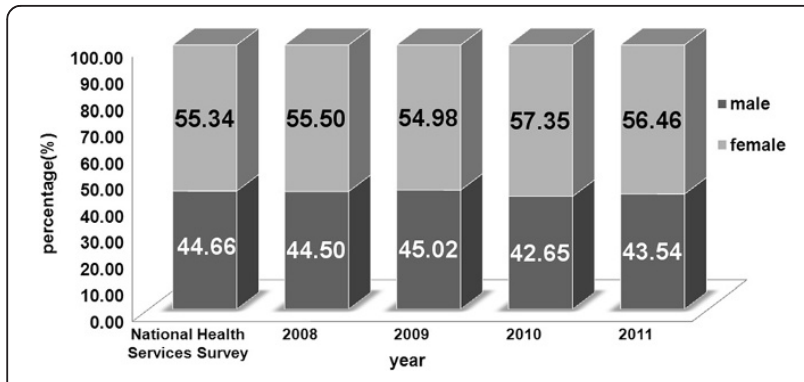

Figure 1 The distribution of the participants by gender. hospitalization service, and then many elderly patients bypass CHIs to go to higher level hospitals for inpatient care service. Moreover, a study elsewhere has found that less than $40 \%$ of the chronic patients had been managed in community in China [27], which leads to a large number of chronic patients receiving specialty services in large hospitals rather than in CHIs.

The proportion of $\mathrm{CHI}$ visitors with low-income was significantly higher than that reported by NHSS, which indicated that low-income patients tended to use CHS. This may be associated with the payment of service costs. In Canada, patients with lower incomes are less likely to visit specialists than those with moderate or high incomes, after adjusting for self-perceived health status and health problems [28]. In China, the medical insurances mainly cover hospitalization and critical illnesses, the reimbursement rates of which reach 75\%, while the reimbursement rate of outpatient costs is only

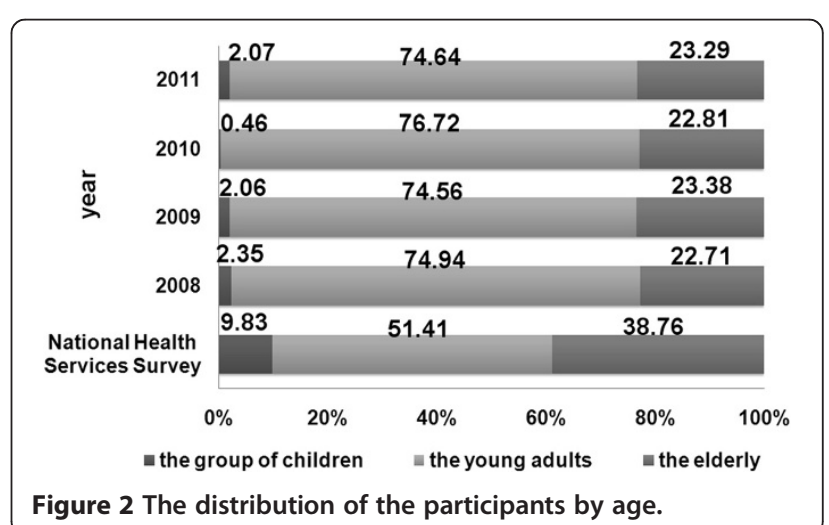




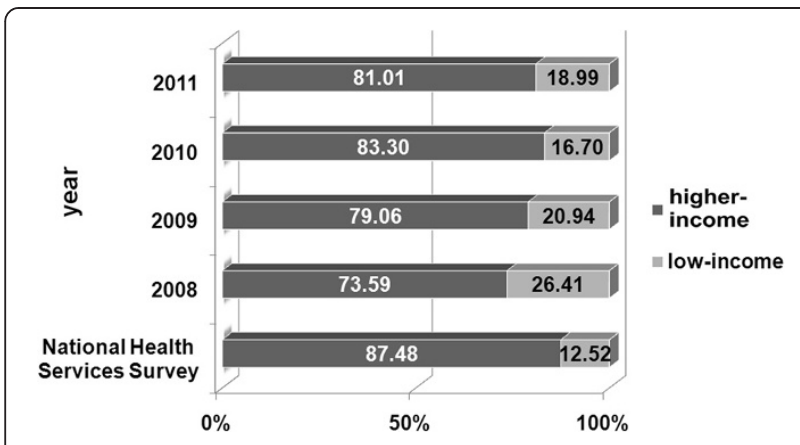

Figure 3 The distribution of the participants by the family average monthly income.

$23 \%$ [29]. As a result, the patients still have to pay a larger proportion of outpatient costs. The main objective of Chinese CHIs is to satisfy the basic health service needs of populations, and the outpatient cost in CHIs is substantially lower than that in higher level hospitals. Thus, given the low price, low-income patients are more likely to go to CHIs for outpatient service. In addition, this study showed that the low-income group had higher satisfaction with the CHS. However, both expenditure and service qualities are important. The skill level of the physicians in CHIs is still lower than in higher level hospitals nowadays. Therefore, most patients with high-income may continue to bypass $\mathrm{CHIs}$ for perceived higher quality specialist care in high level hospitals [30,31].

The poor, as a vulnerable population according to the international standards, are among the target populations of the Chinese CHS [32]. One of the purposes of developing $\mathrm{CHS}$ is to alleviate the problem of low consultation rate of patients, especially vulnerable populations. This study indicated that the low-income patients were more likely to use CHIs for health services, which suggest that developing CHS may attract low-income patients to seek health care, and consequently promote the equity in health service utilization. However, our results also reflect that the Chinese CHIs should strengthen the services for children and the elderly.

The quality of CHS and whether it could meet the demands of patients should be evaluated ultimately by users of the CHIs. The present study found that the visitor satisfactions about $\mathrm{CHI}$ services are above $90 \%$ in terms of service convenience, providers' attitude, respect to patients, and avoidance of excessive examinations or over-prescription. However, the level of satisfaction of $\mathrm{CHI}$ visitors was only about $75 \%$ regarding medical equipment and drug prices. Therefore, equipment of the Chinese CHIs should be much improved in order to meet visitors' needs. Studies suggested that by way of increasing government investment, improving the compensation mechanisms and medical insurance system, drug prices could be decreased effectively $[33,34]$. As to avoidance of excessive examinations or over-prescription, care should be taken in the interpretation of the satisfaction values, because the views of health care providers were not taken into account in this investigation.

The overall satisfactions were the lowest among children visitors (81.2\%) and the highest in the elderly (91.2\%). However, there were no practically meaningful differences

Table 2 The utilized types of the CHS for different characteristic visitors in 2011

\begin{tabular}{|c|c|c|c|c|c|c|c|c|c|c|c|c|}
\hline & \multicolumn{6}{|c|}{ Medical services } & \multicolumn{6}{|c|}{ Public health services } \\
\hline & \multicolumn{2}{|c|}{ Disease diagnosis and treatment } & \multicolumn{2}{|c|}{ Purchasing medicines } & \multicolumn{2}{|c|}{ Rehabilitation } & \multicolumn{2}{|c|}{ Health check } & \multicolumn{2}{|c|}{ Preventive care } & \multicolumn{2}{|c|}{ Health education } \\
\hline & $\mathrm{n}$ & $\%$ & $\mathbf{n}$ & $\%$ & $\mathbf{n}$ & $\%$ & $\mathbf{n}$ & $\%$ & $\mathrm{n}$ & $\%$ & $\mathrm{n}$ & $\%$ \\
\hline \multicolumn{13}{|l|}{ Gender } \\
\hline Male & 3954 & 40.4 & 2273 & 23.3 & 280 & 2.9 & 1477 & 15.1 & 816 & 8.4 & 978 & 10.0 \\
\hline Female & 4998 & 39.8 & 2789 & 22.2 & 319 & 2.5 & 1927 & 15.4 & 1261 & 10.0 & 1263 & 10.1 \\
\hline$x^{2}, p$ & \multicolumn{12}{|c|}{$x^{2}=22.5432, p=0.0004$} \\
\hline \multicolumn{13}{|l|}{ Age } \\
\hline Children & 220 & 49.2 & 16 & 3.6 & 7 & 1.6 & 24 & 5.4 & 175 & 39.2 & 5 & 1.1 \\
\hline Adults & 6576 & 39.6 & 3991 & 24.1 & 420 & 2.5 & 2383 & 14.4 & 1604 & 9.7 & 1617 & 9.8 \\
\hline The elderly & 2140 & 40.7 & 1047 & 19.9 & 172 & 3.3 & 992 & 18.9 & 294 & 5.6 & 615 & 11.7 \\
\hline$x^{2}, p$ & \multicolumn{12}{|c|}{$x^{2}=766.5750, p<0.0001$} \\
\hline \multicolumn{13}{|l|}{ FAMI } \\
\hline Low-income & 1469 & 40.6 & 774 & 21.4 & 110 & 3.0 & 588 & 16.3 & 291 & 8.1 & 385 & 10.6 \\
\hline Higher-income & 7245 & 40.2 & 4085 & 22.7 & 466 & 2.6 & 2709 & 15.0 & 1707 & 9.5 & 1797 & 10.0 \\
\hline$x^{2}, p$ & \multicolumn{12}{|c|}{$x^{2}=15.5804, p=0.0081$} \\
\hline
\end{tabular}

$\mathrm{CHS}=$ community health service, FAMI = family average monthly income.

The ones whose age were less than 15 , between 15 and 65 , and equal to or more than 65 were assigned to group of children, adults and the elderly respectively. 
Table 3 The satisfactions of different characteristic visitors with the CHIs (\%) in 2011

\begin{tabular}{|c|c|c|c|c|c|c|c|c|c|c|c|c|}
\hline & Convenience & $\begin{array}{l}\text { Waiting } \\
\text { time }\end{array}$ & Environment & $\begin{array}{l}\text { Service } \\
\text { attitude }\end{array}$ & $\begin{array}{l}\text { Respect to } \\
\text { patients }\end{array}$ & Equipment & $\begin{array}{l}\text { Explanation and } \\
\text { communication }\end{array}$ & $\begin{array}{l}\text { Service } \\
\text { prices }\end{array}$ & $\begin{array}{l}\text { Drug } \\
\text { prices }\end{array}$ & $\begin{array}{l}\text { Privacy } \\
\text { protection }\end{array}$ & $\begin{array}{l}\text { Avoidance of excessive } \\
\text { examination/over-prescription }\end{array}$ & $\begin{array}{c}\text { Overall } \\
\text { satisfactions }\end{array}$ \\
\hline \multicolumn{13}{|l|}{ Gender } \\
\hline Male & 98.5 & 92.0 & 87.1 & 94.0 & 94.0 & 76.2 & 92.2 & 86.5 & 77.6 & 87.1 & 95.0 & 89.1 \\
\hline Female & 98.7 & 91.7 & 87.8 & 94.5 & 94.4 & 77.1 & 92.2 & 85.9 & 76.8 & 88.2 & 95.8 & 89.4 \\
\hline$x^{2}$ & 1.7557 & 0.5589 & 2.4145 & 3.0453 & 1.6012 & 2.5804 & 0.0009 & 1.4086 & 1.8210 & 6.1338 & 9.6072 & 5.1759 \\
\hline$p$ & 0.1852 & 0.4547 & 0.1202 & 0.0810 & 0.2057 & 0.1082 & 0.9758 & 0.2353 & 0.1772 & 0.0133 & 0.0019 & 0.0229 \\
\hline \multicolumn{13}{|l|}{ Age } \\
\hline Children & 98.3 & 83.2 & 78.6 & 91.9 & 92.3 & 66.8 & 84.9 & 69.3 & 57.7 & 73.9 & 96.7 & 81.2 \\
\hline Adults & 98.4 & 91.2 & 86.7 & 93.9 & 93.7 & 76.4 & 91.7 & 86.1 & 77.0 & 87.3 & 95.3 & 88.2 \\
\hline The elderly & 99.2 & 94.7 & 91.0 & 95.9 & 95.9 & 78.7 & 94.4 & 88.0 & 79.6 & 90.2 & 96.0 & 91.2 \\
\hline$x^{2}$ & 16.5885 & 117.7850 & 105.9991 & 37.4340 & 37.8060 & 39.4893 & 78.2495 & 130.4400 & 121.8400 & 119.0180 & 6.6567 & 495.7900 \\
\hline$p$ & 0.0002 & $<0.0001$ & $<0.0001$ & $<0.0001$ & $<0.0001$ & $<0.0001$ & $<0.0001$ & $<0.0001$ & $<0.0001$ & $<0.0001$ & 0.0359 & $<0.0001$ \\
\hline \multicolumn{13}{|l|}{ FAMI } \\
\hline Low-income & 98.6 & 92.7 & 88.6 & 94.9 & 94.5 & 77.5 & 92.5 & 86.0 & 77.9 & 88.4 & 95.5 & 89.7 \\
\hline Higher-income & 98.6 & 91.1 & 86.4 & 93.6 & 93.9 & 75.8 & 91.8 & 86.4 & 76.7 & 87.1 & 95.9 & 88.9 \\
\hline$x^{2}$ & 0.0426 & 11.1098 & 57.4968 & 11.087 & 17.1879 & 5.4979 & 2.7283 & 0.3856 & 2.8197 & 5.5488 & 1.8883 & 5.0385 \\
\hline$p$ & 0.8364 & 0.0009 & $<0.0001$ & 0.0009 & $<0.0001$ & 0.0190 & 0.0986 & 0.5346 & 0.0931 & 0.0185 & 0.1694 & 0.0248 \\
\hline
\end{tabular}

$\mathrm{CHIs}=$ community health service institutions, FAMI = family average monthly income. The ones whose age were less than 15 , between 15 and 65 , and equal to or more than 65 were assigned to group of children, adults and the elderly respectively. 
in overall satisfaction between females and males, and between low-income and higher-income visitors.

There were small differences in types of health services used in CHIs between visitor groups in terms of gender and income. As to different ages, the utilization rate of preventive care was higher for children, at least partly due to free vaccinations of children in CHIs. Elderly visitors were more likely to use services of purchasing medicine, health check, and health education.

The Chinese government emphasizes the balanced development of basic medical services and public health services provided in CHIs. Nevertheless, the utilization of certain public health services was still insufficient by 2011. The utilization rate of preventive care services was only 9.0\%, which was far less than New Zealand (18.9\%), Poland (29.1\%), America (25.7\%), and some other countries [35-37]. This may be attributed to a lack of sufficient appreciation of the importance of the disease prevention in the community [38], or that public health services have not been fully implemented in CHIs. In England, in order to motivate general practitioners to do well in prevention work, general practitioners' incomes are varied according to the quality and performance of public health services they provide [39]. In Germany, some preventive care services have been covered by medical insurance. In addition, a study suggested that the attitudes towards disease prevention in the community should be changed by health education [40]. China could take similar approaches to improve the utilization of the public health services.

\section{Limitations}

In this study we used intercept survey, which is an economical survey method frequently applied in health service research [41]. Several limitations of our study should also be acknowledged. Firstly, in China, patients could choose health facilities (including CHIs or high level hospitals) for services freely, because of a lack of strict gatekeeper system in community. Findings from this study may be most relevant to China and other countries where there are no gatekeeper systems in community. Secondly, we compared the main characteristics of visitors in our study (represent CHIs) with that of the NHSS, in order to illustrate whether CHIs attracted certain type of patients. The NHSS was a sampling survey of the visitor structure of all level of health institutions nationwide. Thirdly, this was a visitor-based investigation, and the findings could not be related to a population. However, this was a continuous investigation with a large sample size at the national level, which could reflect well the basic situation of CHS in China. Finally, because of the large sample size, some statistically significant differences between groups were small in absolute values.

\section{Conclusions}

A large proportion of low-income group used CHIs for health care services, and CHIs may play an important role in promoting equity in health service utilization. However, the proportions of children and elderly visitors who used CHIs were still low, and services for children and the elderly should be strengthened. Satisfactions of various visitor groups were high in terms of service convenience, providers' attitude, respect to patients and avoidance of excessive examinations or over-prescription. However, visitors in CHIs had lower satisfactions in terms of medical equipment and drug prices. The children had the lowest overall satisfactions than other age groups. The use of public health services provided by CHIs was still generally insufficient.

\section{Abbreviations}

WHO: The World Health Organization; CHS: Community Health Service; CHIs: Community health institutions; PHC: Primary health care; NHSS: National Health Services Survey; FAMl: Family average monthly income.

\section{Competing interests}

We declare we have no competing interests.

\section{Authors' contributions}

$X D$ and $Z \mathrm{~L}$ conceived the idea and prepared a draft review protocol. LL, SC, and $\mathrm{HY}$ provided the data and revised the paper. FS provided suggestions for improvements. $X D, C Y$, and $Y G$ were involved in the data analysis and write up of the manuscript. YW, XY, JX and YS were responsible for the database and all statistical analysis of data for this paper. All authors read and approved the manuscript.

\section{Acknowledgments}

We appreciate Natural Science Foundation of China (NSFC, 71373090) and the fund of Ministry of Health of China (No: NPM040) for supporting this study. We would like to thank Amanda Howe, professor, UK. Norwich Medical School, Faculty of Medicine and Health Science, University of East Anglia, for helpful comments and edits.

\section{Author details}

${ }^{1}$ School of Public Health, Tongji Medical College, Huazhong University of Science and Technology, Wuhan, China. ${ }^{2}$ Norwich Medical School, Faculty of Medicine and Health Science, University of East Anglia, Norwich, UK.

Received: 2 December 2013 Accepted: 12 May 2014

Published: 26 May 2014

\section{References}

1. Hall JJ, Taylor R: Health for all beyond 2000: the demise of the Alma-Ata Declaration and primary health care in developing countries. Med J Aust 2003, 178(1):17-20.

2. De Maeseneer J, Hjortdahl P, Starfield B: Fix what's wrong, not what's right, with general practice in Britain: It has provided better health than government spending deserves. BMJ 2000, 320(7250):1616.

3. Dahrouge $S$, Hogg W, Tuna M, Russell G, Devlin RA, Tugwell P, Kristjansson E: Age equity in different models of primary care practice in Ontario. Can Fam Physician 2011, 57(11):1300-1309.

4. Nteta TP, Mokgatle-Nthabu M, Oguntibeju OO: Utilization of the primary health care services in the Tshwane Region of Gauteng Province, South Africa. Plos one 2010, 5(11):e13909.

5. Xu J, Wang W, Li Y, Zhang J, Pavlova M, Liu H, Yin P, Lu Z: Analysis of factors influencing the outpatient workload at Chinese health centres. BMC Health Serv Res 2010, 10(1):151.

6. Williams A, Cookson R: Equity in health. Handb Health Econ 2000, $1: 1863-1910$. 
7. Marmot M, Friel S, Bell R, Houweling TA, Taylor S: Closing the gap in a generation: health equity through action on the social determinants of health. Lancet 2008, 372(9650):1661

8. Flaskerud JH, Winslow BJ: Conceptualizing vulnerable populations health-related research. Nurs Res 1998, 47(2):69.

9. PR China Ministry of Health: The status of national medical services in 2010. http://www.moh.gov.cn/Zwgkzt/pnb/201103/50847.shtml.

10. Li Y, Xu J, Wang F, Wang B, Liu L, Hou W, Fan H, Tong Y, Zhang J, Lu Z: Overprescribing in China, driven by financial incentives, results in very high use of antibiotics, injections, and corticosteroids. Health Aff 2012, 31(5):1075-1082.

11. Dib HH, Sun P, Minmin Z, Wei S, Li L: Evaluating community health centers in the City of Dalian, China: how satisfied are patients with the medical services provided and their health professionals? Health Place 2010, 16(3):477-488

12. Li X, Zhang T: The comparative analysis of the basic characteristics of the outpatients of the community health service institutions in a city. Chinese Health Quality Management 2008, 15(6):81-83.

13. Ren X, Li N, Gao B, Zhang W, Liu D: The analysis of the diseases of the community health service centers in Chengdu city. Chinese General Practice 2006, 9(17):1472-1473.

14. Yang C, Zheng $Y$, Zhai $H$ : The situation of the medical services of the national community health service sites. Chinese General Practice 2009 7(6):633-635.

15. The Statistic Center of PR China Ministry of Health: An Analysis Report of National Health Services Survey in China, 2008. Beijing: Pekin Union Medical College Press; 2009.

16. PR China Ministry of Health: China Health Statistics Digest of 2010. http:// www.moh.gov.cn/htmlfiles/zwgkzt/ptjnj/year2010/index2010.html.

17. Scott AJ: World Development Report 2009: reshaping economic geography. J Econ Geogr 2009, 9(4):583-586

18. The Statistic Center of PR China Ministry of Health: The statistic communiqué of the national health development in 2008. http://www.gov.cn/gzdt/200904/29/content_1299547.htm.

19. Lu Z, Li Y, Wang F, Wang B, Liu L, Zhou W, Qin G: The Development, effect and concerned issues of pilot work of National Community Health Service System Building in key contact cities-based on the Comprehensive Analysis of the Baseline Survey and Routine Monitoring Data. Chinese J Soc Med 2009, 26(006):321-325.

20. Mo J: The poverty and social security of Hong Kong. Hong Kong: Zhong Hua Book Company; 1993.

21. Bertakis KD, Azari R, Helms LJ, Callahan EJ, Robbins JA: Gender differences in the utilization of health care services. J Fam Pract 2000, 49(2):147-152.

22. Parslow R, Jorm A, Christensen $H$, Jacomb P, Rodgers B: Gender differences in factors affecting use of health services: an analysis of a community study of middle-aged and older Australians. Soc Sci Med (1982) 2004, 59(10):2121.

23. Margolis SA, Al-Marzouqi S, Revel T, Reed RL: Patient satisfaction with primary health care services in the United Arab Emirates. Int J Qual Health Care 2003, 15(3):241-249.

24. Mash B, Fairall L, Adejayan O, Ikpefan O, Kumari J, Mathee S, Okun R, Yogolelo W: A morbidity survey of South African primary care. PLoS One 2012, 7(3):e32358.

25. Cui M, Yin D, Jin C, Chen X, Wang L, Yang H, Wu Q, Wang B, He S, Xu Z, Cao $B$, Chen B: Study on the ability of child health services in primary health institutions. Chinese J Child Health Care 2012, 20(10):872-874

26. Zhou Y, Qian D, Xu L, Zhang Y: Analysis on the trend of change of outpatients' characteristics in urban community health institutions. Chinese Health Resources 2011, 14(4):259-261.

27. Duan X, Qin Z: The analysis of the implementation situation of the basic public health services project in city. Chinese J Pub Health 1999, 16(2):72-75.

28. Dunlop S, Coyte PC, Mclsaac W: Socio-economic status and the utilization of physicians' services: results from the Canadian National Population Health Survey. Soc Sci Med 2000, 51(1):123.

29. Xu S, Xiong G, Zhao J: The analysis of the flow and the cost of the outpatient covered by medical insurance. Chinese J Soc Med 2011, 28(2):131-132.

30. Mills A, Brugha R, Hanson K, McPake B: What can be done about the private health sector in low-income countries? Bull World Health Organ 2002, 80(4):325-330
31. Shen $T$, Cheng $H$, Chen $Z$, Shi R: The survey of the utilization of the community health service and the analysis of the factors of the residents in Shanghai. J Shanghai Jiaotong University (Medical Science) 2010, 1(30):944-963.

32. PR China Ministry of Health: The management measures of community health facilities. http://www.gov.cn/zwgk/2006-08/10/content_359147.htm.

33. Liu Y, Li T, Xia J, Wang F, Lu Z: The Responsibility of Government in Finance of Community Health Service. Chinese J Soc Med 2008, 24(4):224-226.

34. Liu Y, Li T, Zou J, Huang X, Lu Z: Increasing the fund investment to promote the sustainable development of community health service. Chinese Health Economics 2007, 26(9):34-34.

35. Okkes I, Polderman G, Fryer G, Yamada T, Bujak M, Oskam S: The role of family practice in different health care systems. J Fam Pract 2002, 51:72-73.

36. Villani J, Mortensen K: Patient-provider communication and timely receipt of preventive services. Prev Med 2013, 57(5):658-663.

37. Gowin E, Avonts D, Horst-Sikorska W, Ignaszak-Szczepaniak M, Michalak M: Gender makes the difference: the influence of patients' gender on the delivery of preventive services in primary care in Poland. Qual Prim Care 2009, 17(5):343-350

38. Macinko J, Starfield B, Shi L: The contribution of primary care systems to health outcomes within Organization for Economic Cooperation and Development (OECD) countries, 1970-1998. Health Serv Res 2003, 38(3):831-865

39. Qin J, Qin Z: The reward mechanism of the income of the British general practitioners. Foreign Med 1999, 16(2):72-75.

40. Bernabei R, Landi F, Gambassi G, Sgadari A, Zuccala G, Mor V, Rubenstein LZ, Carbonin P: Randomized trial of impact of model of integrated care and case management for older people living in the community. BMJ 1998, 316(7141):1348.

41. Miller KW, Wilder LB, Stillman FA, Becker DM: The feasibility of a streetintercept survey method in an African-American community. Am J Pub Health 1997, 87(4):655-658.

doi:10.1186/1471-2458-14-503

Cite this article as: Dong et al:: Focus on vulnerable populations and promoting equity in health service utilization --an analysis of visitor characteristics and service utilization of the Chinese community health service. BMC Public Health 2014 14:503.

\section{Submit your next manuscript to BioMed Central and take full advantage of:}

- Convenient online submission

- Thorough peer review

- No space constraints or color figure charges

- Immediate publication on acceptance

- Inclusion in PubMed, CAS, Scopus and Google Scholar

- Research which is freely available for redistribution

Submit your manuscript at www.biomedcentral.com/submit
C) Biomed Central 